\title{
Soluble ST2 protein and hospitalizations due to worsening chronic heart failure during a one-year follow-up in a population with reduced ejection fraction
}

\author{
Karolina Wojtczak-Soska ${ }^{2, A-D}$, Agata Sakowicz ${ }^{3, B}$, Tadeusz Pietrucha ${ }^{3, E}$, Kamil Janikowski1, C, D, Małgorzata Lelonek ${ }^{11, A, C, E, F}$ \\ 1 Department of Noninvasive Cardiology, Medical University of Lodz, Poland \\ ${ }^{2}$ Policlinic of Cardiology, Medical University of Lodz, Poland \\ ${ }^{3}$ Department of Medical Biotechnology, Medical University of Lodz, Poland \\ A - research concept and design; $B$ - collection and/or assembly of data; $C$ - data analysis and interpretation; \\ $D$ - writing the article; $E$ - critical revision of the article; $F$ - final approval of article
}

Address for correspondence

Małgorzata Lelonek

E-mail:malgorzata.lelonek@umed.lodz.pl

Funding sources

None declared

Conflict of interest

None declared

Received on September 29, 2015

Revised on February 29, 2016

Accepted on May 4, 2016

\begin{abstract}
Background. Hospitalizations due to worsening chronic heart failure (CHF) are common. However, the relationship between a single measurement of soluble ST2 protein (SST2) and the necessity of hospitalization in CHF is still unclear.
\end{abstract}

Objectives. The aim of this study was to determine the association between a single measurement of SST2 concentration and hospitalizations due to worsening CHF during a one-year follow-up.

Material and methods. The study involved 167 consecutive patients (mean age 63 years, 83\% males) with CHF in stable NYHA classes I-III with left ventricular ejection fraction (LVEF) $\leq 45 \%$ (median 29.65\%, range 13-45\%). Fifty-six variables were analyzed (clinical factors, basic laboratory results on admission, standard 12-lead ECG, echocardiography and coronary arteriography results). Information about hospitalizations due to worsening CHF was obtained during telephone interviews conducted 12 months after discharge from the cardiac ward. In order to define factors associated with hospitalization, uni- and multivariate regression analyses were performed.

Results. A total of 53 patients from the study group (38\%) were hospitalized due to worsening CHF. They included a higher percentage of males ( $p=0.042)$, higher concentrations of sST2 ( $p=0.049)$, and glucose $(p=0.010)$. The multivariate analysis (for model $\chi^{2}=17.235 ; p<0.001$ ) revealed that glucose and sST2 were independently associated with hospitalization due to worsening CHF during the 1-year observation $(p<0.001)$.

Conclusions. In patients with stable mild to moderate CHF with reduced EF, a single measurement of SST2 protein and glucose were independent variables for hospitalization due to worsening CHF over a 1-year follow-up period. The defined prognostic model including SST2 and fasting glucose better identified patients without HF-related hospitalizations.

Key words: prognosis, biomarkers, hospitalization, heart failure, ventricular dysfunction

DOI

10.17219/acem/63005

Copyright

Copyright by Author(s)

This is an article distributed under the terms of the

Creative Commons Attribution Non-Commercial License

(http://creativecommons.org/licenses/by-nc-nd/4.0/) 
Chronic heart failure (CHF) is becoming an increasing clinical and economical problem. According to the estimates of the European Society of Cardiology, heart failure (HF) absorbs approx. $2 \%$ of the funds allocated to health care, including a significant proportion for repeated hospitalizations. ${ }^{1}$ In the USA, unplanned rehospitalizations cost Medicare 17.4 billion dollars, and HF is the most common cause. ${ }^{2}$ Decompensation of CHF represents $80 \%$ of all hospitalizations due to $\mathrm{HF}^{3}$ One of the most important aspects is the frequency of hospitalization and readmission of patients with HF. The rate of rehospitalization within 30 days of discharge ranges from 15 to $25 \% .^{2,4,5}$ In other published studies, the incidence of hospital readmission approaches $45 \%$ at 6 months. ${ }^{6}$

Although some biomarkers have established roles in the prognosis for $\mathrm{CHF}$, improvement of risk stratification in HF continues to be developed using new markers, and among these, soluble ST2 protein (sST2) has come of age. SST2 is part of the cardioprotective signaling pathway involving interleukin-33. Biomechanical strain in cardiomyocytes and remodeling fibrosis affect sST2 concentration in the serum. The prognostic utility of sST2 protein has recently been documented in acute and chronic heart failure. There have been several papers suggesting the usefulness of SST2 in predicting adverse outcomes, but the relationship between a single measurement of sST2 protein and the necessity of hospitalization in CHF still remains unknown. ${ }^{7-20}$ The aim of this study was to determine the association between a single measurement of sST2 concentration and hospitalizations due to worsening $\mathrm{CHF}$ in a 1-year follow-up period.

\section{Material and methods}

The study included 167 consecutive patients diagnosed at the Department of Noninvasive Cardiology at the Medical University of Lodz (Poland). The inclusion criteria were as follows: stable (defined as at least 4 weeks without CHF exacerbation); mild to moderate CHF categorized as NYHA (New York Heart Association) class I-III; left ventricular ejection fraction (LVEF) lower than or equal to 45\%; optimal treatment of HF according to the guidelines of the European Society of Cardiology (ESC). ${ }^{1}$ The patients' hemodynamic state was stable and the reason for admission to the hospital was to determinate HF etiology and to establish appropriate management. The exclusion criteria were NYHA class IV, acute heart failure, acute coronary syndrome, inflammatory states and thyroid dysfunction.

The study was approved by the Bioethics Committee at the Medical University of Lodz (no. RNN/79/10/KE) and all the patients signed informed consent form to participate in the study.

The patients' clinical history, basic laboratory results and standard 12-lead ECG were assessed upon their ad- mission to the hospital. The results of echocardiography and coronary arteriography were obtained according to American Society of Echocardiography/European Association of Echocardiography (ASE/EAE) and ESC recommendations.

The analyses included 58 variables:

- clinical features such as NYHA class, age, body mass index (BMI), arterial blood pressure, smoking status; coincidence of arterial hypertension, diabetes mellitus (DM), stroke, myocardial infarction (MI), peripheral arterial disease or chronic lung diseases;

- selected laboratory results such as morphology, sodium, creatinine, estimated glomerular filtration rate (e-GFR), serum lipid concentrations, C-reactive protein (CRP), high-sensitivity troponin $\mathrm{T}$ (hsTnT) and $\mathrm{N}$-terminal prohormone B-type natriuretic peptide (NT-proBNP);

- electrocardiographic variables: heart rhythm (sinus rhythm or atrial arrhythmias), heart rate, left bundle branch block (LBBB), QRS duration, QTc;

- selected echocardiographic results (M-mode, 2-dimensional and Doppler echocardiographic examinations): left atrial diameter (LA), left ventricular systolic dimensions (LVESD), left ventricular diastolic dimensions (LVEDD), left ventricular end-systolic volume (LVESV), left ventricular end-diastolic volume (LVEDV), and left ventricular ejection fraction (LVEF);

- coronary arteriography results (stenosis $>50 \%$ of left main coronary artery, $>75 \%$ of other coronary arteries; analyzed as 1-, 2-, or 3-vessel disease) to determine the etiology of HF (ischemic vs non-ischemic). Coronary arteriography was performed by a radial or femoral approach with visual quantification of sclerotic alteration.

Blood samples $(5 \mathrm{~mL})$ to determine sST2 concentration were collected upon admission to the hospital using standard collection techniques into vacuum tubes containing a clot activator. The samples were centrifuged for $5 \mathrm{~min}$ at $3000 \mathrm{rpm}$ after the formation of a clot, and the supernatant (serum) was immediately separated and frozen at $-76^{\circ} \mathrm{C}$. Then, after thawing the serum, the soluble ST2 level was measured by quantitative assay using a sandwich ELISA kit (Medical \& Biological Laboratories Co., Ltd, Nagoya, Japan) validated for use with human serum. This kit uses 2 monoclonal antibodies against 2 different epitopes of human sST2. The serum samples were incubated in microwells coated with the first antihuman sST2 monoclonal antibody. After the washing stage, the second incubation with the peroxidase conjugated antihuman sST2 monoclonal antibody was conducted. After further washing, the peroxidase substrate was added to each well and the optical density was measured at $450 \mathrm{~nm}$ using a microplate reader.

A telephone interview with each patient was conducted by the cardiologist 12 months after discharge from the 
cardiac ward, and information about hospitalizations due to decompensation of $\mathrm{CHF}$ was collected; the patients were always asked to read the discharge diagnosis aloud. The patients were divided into groups and analyzed depending on the occurrence of hospitalization due to decompensation of CHF.

The statistical calculations were performed using the STATISTICA PL v. 9.0 software package (StatSoft, Inc. Tulsa, USA) and IBM SPSS Statistics for Windows v. 19 (IBM Corp., Armonk, USA).

For measurable variables, basic descriptive characteristics - the mean, median, maximum and minimum values, interquartile range (IQR, Q25 - Q75) and standard deviation (SD) - were provided. For qualitative variables, the number of observations $(\mathrm{N})$ and the corresponding percentage (\%) were indicated. Normality was tested using the Shapiro-Wilk test.

For comparison of 2 independent groups of quantitative variables, Student's t-test (in the case of normal distribution in both groups) or the nonparametric Mann-Whitney U-test (in the absence of normal distribution) was used. To verify the relationship between qualitative variables, a $\chi^{2}$ test of independence or a $\chi^{2}$ test of independence with Yates' correction (in lower numbers) was used.

For statistically significant quantitative variables, ROC curves were drawn and the optimal cut-off points were determined. The sensitivity, specificity, positive and negative predictive value (PPV and NPV), odds ratio (OR) and a $95 \%$ confidence interval $(95 \% \mathrm{CI})$ were also assigned.

In order to determine the factors related to hospitalizations, univariate and multivariate forward stepwise regression analyses were performed. Variables that reached $\mathrm{p}<0.1$ in univariate analyses were used in the stepwise logistic regression models. Results were considered statistically significant at $\mathrm{p}<0.05$. Kaplan-Meier survival curves were created for rehospitalization.

\section{Results}

The mean age of the patients included in the study was 63 years +/- 11.58. The majority of patients were men (83\%), mainly in NYHA class III (72\%), with mean LVEF $29.65 \%+/-7.83$ (range: $13-45 \%$ ). The patients studied were burdened with many comorbidities: coronary artery disease (54\%), hypertension (53\%), chronic kidney disease (22\%), chronic lung disease (12\%) and disorders of carbohydrate metabolism (37\%). The mean sST 2 concentration was $0.65 \mathrm{ng} / \mathrm{mL}+/-0.7$. The only factor independently associated with the level of sST2 was the QRS complex duration (OR $=1.013$; 95\%CI [1.001-1.025]; $\mathrm{p}=0.03)$.

The patients who were rehospitalized during the follow-up period due to decompensation of CHF ( $\mathrm{n}=53$; $38 \%$ ) were mostly male and had higher levels of sST2 and glucose (Table 1). The average time to the first re- hospitalization was 6.7 months $+/-3.45$. The rehospitalization rates in the first month, 3 months and 6 months after discharge were $5.6 \%, 20.7 \%$ and $52.8 \%$ respectively. Among all the patients, 24 died due to HF $(n=20)$ or MI $(n=4)$ during the observation period and were excluded from the analysis in the present study; the data on those patients were analyzed in detail in a previous paper. ${ }^{17}$

In a multi-variate forward stepwise regression analysis both sST2 and glucose are independently associated with hospitalization due to decompensation of CHF during the 1-year observation period (Table 2). If sST2 protein concentration increased by one unit, the risk of hospitalization increased more than twofold. On the other hand, if the concentration of serum fasting glucose increased by 1 unit, the risk of hospitalization increased by $50.5 \%$.

Using ROC analysis, a cut-off point value for sST2 $\geq 0.3389 \mathrm{ng} / \mathrm{mL}$ was determined (AUC $[95 \% \mathrm{CI}]=0.599$ [0.503-0.696]; $\mathrm{p}=0.049$ ) with a sensitivity of $58.49 \%$, specificity $55.17 \%$, and positive and negative predictive values of $44.3 \%$ and $68.6 \%$ respectively. From the ROC analysis a cut-off point value for glucose $>5.918 \mathrm{mmol} / \mathrm{L}$ was determined (AUC [95\%CI] $=0.637$ [0.535-0.739], $\mathrm{p}=0.01$ ) with a sensitivity of $62.5 \%$, specificity $55 \%$, and positive and negative predictive values of $45.45 \%$ and $70.97 \%$ respectively. A prognostic model containing both variables had a NPV of $88.7 \%$ and a PPV of $39.1 \%$.

Survival curves for hospitalization during the 1-year observation period were determined using the KaplanMeier method (Fig. 1). In comparison to a high concentration of sST2 $\geq 0.3389 \mathrm{ng} / \mathrm{mL}$, low concentrations of sST2 $<0.3389 \mathrm{ng} / \mathrm{mL}$, below the threshold from the ROC curve, indicated a better prognosis, and the probability of non-occurrence of HF-related hospitalization increased from 0.58 to 0.7 . This model showed a trend toward statistically significance $(p=0.065)$ in the study population.

Fig. 1. Kaplan-Meier curves for hospitalizations based on sST2 concentrations

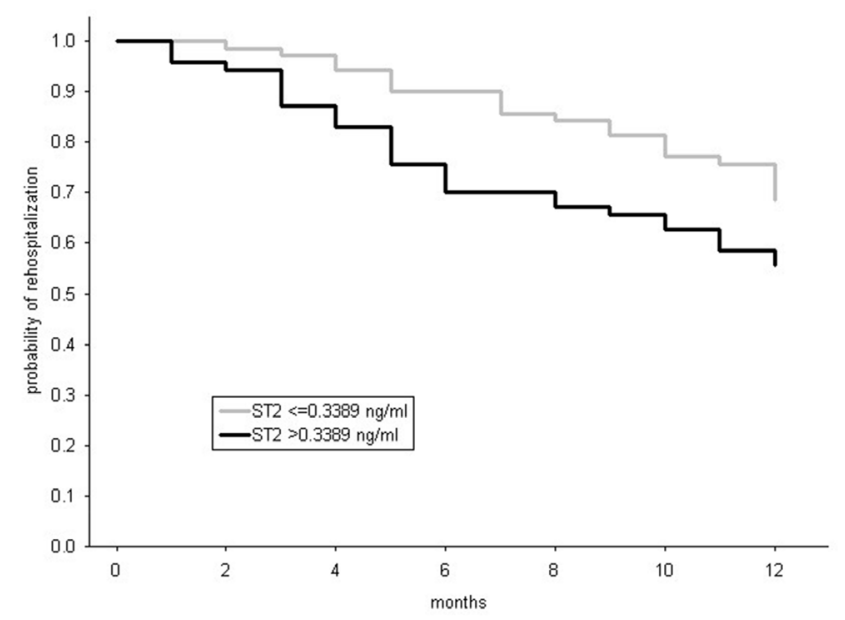


Table 1. Selected patient characteristics in relation to hospitalization due to decompensation of chronic heart failure

\begin{tabular}{|c|c|c|c|c|c|}
\hline \multirow{2}{*}{ Variables } & \multicolumn{2}{|c|}{$\begin{array}{l}\text { Without hospitalization } \\
\qquad \mathrm{n}=114\end{array}$} & \multicolumn{2}{|c|}{$\begin{array}{l}\text { Hospitalization } \\
n=53\end{array}$} & \multirow{2}{*}{$p$-value } \\
\hline & $\begin{array}{c}\text { n or mean }+/- \text { SD } \\
\text { (range) }\end{array}$ & $\%$ or median (IQR) & $\begin{array}{c}\text { n or mean }+/- \text { SD } \\
\text { (range) }\end{array}$ & $\%$ or median (IQR) & \\
\hline \multicolumn{6}{|c|}{ Demographic and clinical } \\
\hline Male. & 70 & 80.46 & 50 & 94.34 & 0.042 \\
\hline Age [years] & $\begin{array}{c}63.33+/-12.2 \\
(24-87)\end{array}$ & $\begin{array}{c}64 \\
(55-73)\end{array}$ & $62.3+/-10.42(38-82)$ & $\begin{array}{c}63 \\
(57-67)\end{array}$ & 0.610 \\
\hline Body mass index $\left[\mathrm{kg} / \mathrm{m}^{2}\right]$ & $\begin{array}{l}26.53+/-3.98 \\
(16.6-39.26)\end{array}$ & $\begin{array}{c}26.5 \\
(23.67-29.07)\end{array}$ & $\begin{array}{l}26.92+/-3.65 \\
(20.05-35.32)\end{array}$ & $\begin{array}{c}26.4 \\
(24.3-29.36)\end{array}$ & 0.568 \\
\hline $\begin{array}{l}\text { NYHA class. } \\
\text { । } \\
\| \\
\text { III }\end{array}$ & $\begin{array}{c}4 \\
25 \\
58\end{array}$ & $\begin{array}{l}4.60 \\
28.74 \\
66.67\end{array}$ & $\begin{array}{c}2 \\
11 \\
40\end{array}$ & $\begin{array}{c}3.77 \\
20.75 \\
75.47\end{array}$ & 0.540 \\
\hline Ischaemic HF & 48 & 55.17 & 32 & 60.38 & 0.546 \\
\hline $\begin{array}{l}\text { Former or current } \\
\text { smoking }\end{array}$ & 46 & 62.16 & 33 & 68.75 & 0.457 \\
\hline HA & 42 & 50.00 & 32 & 62.75 & 0.149 \\
\hline DM & 27 & 32.14 & 23 & 45.10 & 0.130 \\
\hline Peripheral sclerosis & 9 & 10.59 & 9 & 17.65 & 0.240 \\
\hline Ml & 45 & 51.72 & 31 & 58.49 & 0.436 \\
\hline Chronic lung disease & 10 & 11.90 & 4 & 7.48 & 0.646 \\
\hline $\begin{array}{l}\text { Systolic blood pressure } \\
{[\mathrm{mm} \mathrm{Hg}]}\end{array}$ & $\begin{array}{c}120.41+/-17.97 \\
(90-190)^{*}\end{array}$ & $\begin{array}{c}120 \\
(110-130)\end{array}$ & $\begin{array}{l}120.93+/-17.69 \\
\quad(85-164)\end{array}$ & $\begin{array}{c}120 \\
(110-130)\end{array}$ & 0.761 \\
\hline $\begin{array}{l}\text { Diastolic blood pressure } \\
{[\mathrm{mm} \mathrm{Hg}]}\end{array}$ & $\begin{array}{c}72.18+/-9.37 \\
(55-100)^{*}\end{array}$ & $\begin{array}{c}70 \\
(70-80)\end{array}$ & $\begin{array}{c}75.32+/-10.79 \\
(60-100)^{*}\end{array}$ & $\begin{array}{c}75 \\
(70-80)\end{array}$ & 0.102 \\
\hline \multicolumn{6}{|c|}{ ECG } \\
\hline Atrial fibrillation & 22 & 26.19 & 10 & 18.87 & 0.324 \\
\hline LBBB & 23 & 27.38 & 14 & 27.45 & 0.993 \\
\hline Heart rate [bpm] & $\begin{array}{c}77.16+/-20.17 \\
(53-170)^{*}\end{array}$ & $\begin{array}{c}70 \\
(65-83)\end{array}$ & $\begin{array}{c}79.15+/-15.32 \\
(55-120)^{*}\end{array}$ & $\begin{array}{c}80 \\
(65-87)\end{array}$ & 0.133 \\
\hline QRS duration [ms] & $\begin{array}{c}109.77+/-28.4 \\
(60-180)^{*}\end{array}$ & $\begin{array}{c}102 \\
(80-120)\end{array}$ & $\begin{array}{c}116.04+/-29.51 \\
(80-200)^{*}\end{array}$ & $\begin{array}{c}100 \\
(100-136)\end{array}$ & 0.368 \\
\hline QTc [ms] & $\begin{array}{l}387.1+/-52.45 \\
(260-520)\end{array}$ & $\begin{array}{c}380 \\
(340-420)\end{array}$ & $\begin{array}{l}395.2+/-44.1^{*} \\
(280-520)\end{array}$ & $\begin{array}{c}400 \\
(360-420)\end{array}$ & 0.294 \\
\hline \multicolumn{6}{|c|}{ Echocardiography } \\
\hline LVEF (\%) & $\begin{array}{l}30.18+/-7.75 \\
\quad(13-45)\end{array}$ & $\begin{array}{c}30 \\
(24-36)\end{array}$ & $\begin{array}{c}29.02+/-7.33 \\
(14-45)\end{array}$ & $\begin{array}{c}29 \\
(24-34)\end{array}$ & 0.380 \\
\hline LVESD [cm] & $\begin{array}{c}5.35+/-0.9 \\
(3.5-8)\end{array}$ & $\begin{array}{c}5.33 \\
(4.7-5.94)\end{array}$ & $\begin{array}{l}5.59+/-0.88 \\
(3.4-7.2)\end{array}$ & $\begin{array}{c}5.8 \\
(4.9-6.18)\end{array}$ & 0.165 \\
\hline LVEDD [cm] & $\begin{array}{c}6.64+/-0.84 \\
\quad(5-9.2)\end{array}$ & $\begin{array}{c}6.5 \\
(6-7.2)\end{array}$ & $\begin{array}{l}6.89+/-0.87 \\
(4.7-8.7)\end{array}$ & $\begin{array}{c}7 \\
(6.4-7.5)\end{array}$ & 0.123 \\
\hline
\end{tabular}

The table shows selected variables relevant to the context of the article. *variables with non-parametric distribution; SD - standard deviation; NYHA - New York Heart Association; HF - heart failure; HA - hypertension; DM - diabetes mellitus; MI - myocardial infarction; ECG - electrocardiogram; LBBB - left bundle branch block; LVEF - left ventricular ejection fraction; LVESD - left ventricular end-systolic diameter; LVEDD - left ventricular end-diastolic diameter; LVESV - left ventricular end-systolic volume; LVEDV - left ventricular end-diastolic volume; LA - left atrium; CAD - coronary artery disease; hsTnT - high sensitivity troponin T; hsCRP - high-sensitivity C-reactive protein; e-GFR - estimated glomerular filtration rate. 
Table 1. Selected patient characteristics in relation to hospitalization due to decompensation of chronic heart failure (cont.)

\begin{tabular}{|c|c|c|c|c|c|}
\hline \multirow{2}{*}{ Variables } & \multicolumn{2}{|c|}{$\begin{array}{l}\text { Without hospitalization } \\
\qquad n=114\end{array}$} & \multicolumn{2}{|c|}{$\begin{array}{l}\text { Hospitalization } \\
\qquad n=53\end{array}$} & \multirow{2}{*}{$p$-value } \\
\hline & $\begin{array}{c}\text { n or mean }+/- \text { SD } \\
\text { (range) }\end{array}$ & $\%$ or median (IQR) & $\begin{array}{c}\mathrm{n} \text { or mean }+/-\mathrm{SD} \\
\text { (range) }\end{array}$ & $\%$ or median (IQR) & \\
\hline \multicolumn{6}{|c|}{ Echocardiography } \\
\hline LVESV [mL] & $\begin{array}{l}134.87+/-55.89^{*} \\
(46-343)\end{array}$ & $\begin{array}{c}122 \\
(92-170)\end{array}$ & $\begin{array}{c}156.02+/-69.54 \\
(34-364)\end{array}$ & $\begin{array}{c}145 \\
(114-187)\end{array}$ & 0.081 \\
\hline LVEDV [mL] & $\begin{array}{l}190.71+/-68.49^{*} \\
\quad(87-477)\end{array}$ & $\begin{array}{c}182 \\
(140-230)\end{array}$ & $\begin{array}{l}215.1+/-83.74 \\
\quad(55-449)\end{array}$ & $\begin{array}{c}206 \\
(169-245)\end{array}$ & 0.076 \\
\hline LA [cm] & $\begin{array}{l}5.88+/-0.98 \\
(3.5-8.6)\end{array}$ & $\begin{array}{c}5.7 \\
(5.3-6.4)\end{array}$ & $\begin{array}{l}6.09+/-0.78 \\
(3.5-7.8)\end{array}$ & $\begin{array}{c}6 \\
(5.7-6.6)\end{array}$ & 0.206 \\
\hline \multicolumn{6}{|c|}{ Coronarography (extent of CAD) } \\
\hline 1 vessel. & 11 & 18.97 & 11 & 28.95 & \\
\hline 2 vessels. & 16 & 27.59 & 10 & 26.32 & 0.611 \\
\hline 3 vessels. & 8 & 13.79 & 6 & 15.79 & \\
\hline \multicolumn{6}{|c|}{ Biochemical } \\
\hline $\mathrm{sST} 2 \mathrm{ng} / \mathrm{mL}$ & $\begin{array}{l}0.5+/-0.4 \\
(0.19-2.25)^{*}\end{array}$ & $\begin{array}{c}0.31 \\
(0.27-0.53)\end{array}$ & $\begin{array}{l}0.81+/-0.96 \\
(0.25-4.3)^{*}\end{array}$ & $\begin{array}{c}0.38 \\
(0.29-0.85)\end{array}$ & 0.049 \\
\hline NT-proBNP (mg/dL) & $\begin{array}{l}2759+/-3041 \\
(197-13863)^{*}\end{array}$ & $\begin{array}{c}1881 \\
(761-3078)\end{array}$ & $\begin{array}{l}3445+/-5399 \\
(333-35000)^{*}\end{array}$ & $\begin{array}{c}1912 \\
(1001-3985)\end{array}$ & 0.408 \\
\hline hsTnT [mg/L] & $\begin{array}{l}0.048+/-0.072 \\
(0.004-0.36)^{*}\end{array}$ & $\begin{array}{c}0.023 \\
(0.014-0.053)\end{array}$ & $\begin{array}{l}0.039+/-0.033 \\
(0.004-0.14)^{*}\end{array}$ & $\begin{array}{c}0.032 \\
(0.016-0.045)\end{array}$ & 0.396 \\
\hline hsCRP [mg/L] & $\begin{array}{c}7.15+/-14.46^{*} \\
(0.2-97)\end{array}$ & $\begin{array}{c}3 \\
(0.8-7)\end{array}$ & $\begin{array}{l}6.44+/-9.66^{*} \\
(0.5-47.8)\end{array}$ & $\begin{array}{c}3.4 \\
(0.9-6.7)\end{array}$ & 0.683 \\
\hline Creatinine $[\mathrm{mg} / \mathrm{L}]$ & $\begin{array}{l}89.46+/-22.13^{*} \\
(49-168.11)\end{array}$ & $\begin{array}{c}88.48 \\
(71.5-97.33)\end{array}$ & $\begin{array}{c}89.61+/-26.78^{*} \\
(53.09-194.66)\end{array}$ & $\begin{array}{c}85 \\
(70.78-97.33)\end{array}$ & 0.576 \\
\hline $\mathrm{e}-\mathrm{GFR}\left[\mathrm{mL} / \mathrm{min} / 1.73 \mathrm{~m}^{2}\right]$ & $\begin{array}{l}84.22+/-29.29 \\
(27-156.32)\end{array}$ & $\begin{array}{c}81 \\
(63.66-105.2)\end{array}$ & $\begin{array}{c}94.55+/-36.45^{*} \\
(27.9-223.5)\end{array}$ & $\begin{array}{c}91 \\
(70.486-113)\end{array}$ & 0.151 \\
\hline Sodium $[\mathrm{mmol} / \mathrm{L}]$ & $\begin{array}{c}136.95+/-3.09^{*} \\
(127-143)\end{array}$ & $\begin{array}{c}137 \\
(136-139)\end{array}$ & $\begin{array}{c}137.04+/-3.28 \\
(129-144)\end{array}$ & $\begin{array}{c}138 \\
(135-139)\end{array}$ & 0.743 \\
\hline Glucose [mmol/L] & $\begin{array}{l}5.89+/-0.93^{*} \\
(4.37-9.3)\end{array}$ & $\begin{array}{c}5.82 \\
(5.26-6.13)\end{array}$ & $\begin{array}{c}6.89+/-2.49^{*} \\
(2.63-16.2)\end{array}$ & $\begin{array}{c}6.05 \\
(5.63-7.39)\end{array}$ & 0.010 \\
\hline
\end{tabular}

The table shows selected variables relevant to the context of the article. *variables with non-parametric distribution; SD - standard deviation; NYHA - New York Heart Association; HF - heart failure; HA - hypertension; DM - diabetes mellitus; MI - myocardial infarction; ECG - electrocardiogram; LBBB - left bundle branch block; LVEF - left ventricular ejection fraction; LVESD - left ventricular end-systolic diameter; LVEDD - left ventricular end-diastolic diameter; LVESV - left ventricular end-systolic volume; LVEDV - left ventricular end-diastolic volume; LA - left atrium; CAD - coronary artery disease; hsTnT - high sensitivity troponin T; hsCRP - high-sensitivity C-reactive protein; e-GFR - estimated glomerular filtration rate.

Table 2. Model of multivariate stepwise logistic regression analysis for hospitalization due to worsening chronic heart failure

\begin{tabular}{|l|c|c|c|c|c|c|}
\hline \multicolumn{1}{|c|}{ Variables } & $\begin{array}{c}\text { B - parameter } \\
\text { estimation }\end{array}$ & $\begin{array}{c}\text { Standard } \\
\text { error (SE) }\end{array}$ & p-value & $\begin{array}{c}\text { Exp(B) - odds } \\
\text { ratio OR }\end{array}$ & 95\% confidence interval for OR \\
\hline SST2 & 0.801 & 0.335 & 0.017 & 2.228 & 1.156 & 4.296 \\
\hline Glucose & 0.408 & 0.149 & 0.006 & 1.505 & 1.123 & 2.015 \\
\hline
\end{tabular}




\section{Discussion}

The present study revealed that in a population with stable mild-to-moderate chronic heart failure and $\mathrm{EF} \leq 45 \%$, a single measurement of sST2 protein concentration is an independent variable for HF-related hospitalization during a 1-year observation period.

In most studies HF-related hospitalization occurs in conjunction with death as a composite endpoint, and most studies have been performed in populations that have experienced an HF event, to assess the prognostic role of biomarkers. Only Felker et al. described an association of ST2 and long-term outcomes (over a period of 2.5 years) including death, hospitalization and functional capacity ambulatory population with $\mathrm{CHF}$ and $\mathrm{EF}<35 \% .{ }^{21}$

In the Controlled Rosuvastatin Multinational Trial in Heart Failure (the CORONA study) on 1449 patients with $\mathrm{CHF}$ of ischemic origin with $\mathrm{LVEF} \leq 40 \%$, it was found that SST2 is an independent predictor of hospitalization due to worsening CHF (HR 1.30, 95\% CI [1.04-1.62], $\mathrm{p}=0.02)$; of death in the course of increasingly severe CHF (HR 1.57, 95\% CI [1.05-2.34, p = 0.03); and of hospitalization due to cardiovascular events (HR 1.28, 95\% CI [1.07$1.52], \mathrm{p}=0.006) .^{22}$ In the present study group, there was a wide spectrum of patients with CHF of both ischemic and non-ischemic etiology. The HF etiology was not associated with rehospitalization, and sST2 was not related to the etiology of HF. In the Valsartan Heart Failure Trial sST2 was significantly ( $<<0.0001)$ associated with the risk of hospitalization for heart failure. ${ }^{23}$

In CHF, subsequent measurements of either BNP or NT-proBNP levels provide independent information regarding the risk for disease progression across a wide spectrum of adverse outcomes: ventricular remodelling, malignant ventricular arrhythmias, hospitalization for $\mathrm{HF}$, the need for transplantation, as well as death. ${ }^{24,25}$ In $\mathrm{CHF}$, measurements of natriuretic peptide (NP) levels provide independent information regarding the risk for hospitalization for HF, and NP-guided therapy can reduce all-cause mortality and HF-related hospitalizations. ${ }^{24,26}$ The present study did not find a correlation between hospitalization and NTproBNP. In contrast to other studies, in which patients entering the survey were hospitalized due to HF decompensation, in the present study they were in clinical stable CHF. Therefore further study of this issue is needed in mild-to-moderate $\mathrm{CHF}$.

An interesting finding is the lack of association of traditional risk factors and the risk of HF-related hospitalization. Similar findings were also revealed in a previous publication by the present authors. ${ }^{27}$ It should be emphasized that the study population had stable mild-tomoderate CHF and $\mathrm{EF} \leq 45 \%$ that was optimally treated. The hospitalization during which the patients were enrolled in the study was not due to exacerbation of HF (it was to determinate HF etiology and to establish appro- priate management), and the period of observation was short (1 year).

In the authors' opinion, these 4 aspects (the population, the optimal treatment, the nature of the primary hospitalization and the short-term observation) were the reason for the absence of any relationship between other risk factors and hospitalization due to worsening HF. Moreover, according the International ST2 Consensus Panel, sST2 is one of the most powerful predictors of HF complications. ${ }^{28}$ According to that document, sST2 is considered to be especially useful in the prognosis of HF events such as worsening HF and the risk of hospitalization, arrhythmia or death from HF. This emphasizes even more the role of sST2 as a prognostic factor for hospitalization due to worsening HF in the patients in the current study.

The present study is based on a single measurement of sST2 and NT-proBNP in stable CHF patients, whereas most studies on the prognostic utility of NP were conducted using serial measurements of NP.

Another important finding of the present study is the independent correlation between the fasting glucose serum level and HF-related hospitalization. This is consistent with other studies showing an association between high concentrations of glucose and a worse prognosis in CHF. ${ }^{29,30}$ In a study by Gotsman et al., impaired fasting glucose was a predictor of increased cardiac-related hospitalizations (HR 1.17, 95\% CI 1.00-1.35, p < 0.05). ${ }^{30}$

Recently more and more attention is being paid to the problem of hospitalization due to CHF decompensation, which means that identifying factors that affect its occurrence is very important. Reports of found new variables associated with hospitalization have been published, such as heart rate $\mathrm{e}^{31}$, which was not a factor influencing hospitalization in the present study. This was probably due to the study population undergoing optimal treatment that resulted in satisfactory heart rates.

Among biomarkers, NP has an established position as a predictor of HF-related hospitalization. Beside NP, more and more has been written about novel biomarkers related to cardiac remodeling and fibrosis. Gaggin et al. ${ }^{32}$ confirmed that sST2 appears to be a more useful biomarker than others, such as GDF-15 and galectin-3 in the population of patients with $\mathrm{CHF} .{ }^{33}$

In addition, the present study found that QRS duration is independently associated with sST2 levels. It is well known that the duration of the QRS has prognostic value in HF and is a criterion in qualification for electrotherapy. ${ }^{34}$ Thus, a relationship between sST2 and QRS is plausible, but until now nothing has been stated about that relationship in the literature.

One of the limitations of the present study is the use of an older generation of sST2 test, which is less sensitive than newer ones. Among several highly sensitive assays, the most popular is the Presage ${ }^{\circledR}$ ST2 Assay (Critical Diagnostics, San Diego, USA), which has FDA approval. The cut-off point for adverse outcomes in $\mathrm{HF}$ is $\geq 35 \mathrm{ng} / \mathrm{mL}$, which resulted in 
this ST2 assay being taken into account in the ACCF/AHA Guideline for the Management of Heart Failure 2013. ${ }^{35}$ The present study used another cut-off point for SST2 concentration, which was due to the methodology of sST2 measurement (the MBL ST2 assay).

It is also worth mentioning the Aspect Plus Reader ST2 test (Critical Diagnostics, San Diego, USA), a rapid lateral flow immunoassay for the quantitative determination of ST2 in venous EDTA anticoagulated plasma, intended for clinical practice. The test can clarify ST2 levels at the bedside, guide clinical practice and improve risk stratification in CHF patients.

Another limitation of this study is the relatively small group of patients and the lack of control group; and some of the results are borderline significant, which is probably also due to the relatively small population. Also, followups based on telephone contact without the possibility of firsthand examination of the discharge cards from HF hospitalizations is a limitation.

It is possible that the impact of the HF drugs used by the patients enrolled in the study could have influenced the number of hospitalizations due to worsening HF. However, neither the HF drugs nor the doses were included in the analysis, which is also a limitation of the study.

In the current literature the cut-off point for ST2 $\geq 35 \mathrm{ng} /$ $\mathrm{mL}$ was described for ambulatory CHF-patients with the risk of hospitalization. ${ }^{21}$ The present study, however, revealed that $\mathrm{sST} 2$ concentration better identifies patients without HF-hospitalizations. There is a need for further investigation of the role of sST2 in CHF, based on personalized cardiovascular care with the Aspect Plus Reader ST2 test.

In patients with stable mild to moderate chronic heart failure with reduced $\mathrm{EF} \leq 45 \%$, single measurements of sST2 protein and fasting glucose were independent variables for hospitalization due to worsening $\mathrm{CHF}$ during the 1-year follow-up period. In the study population the defined prognostic model consisting of sST2 and glucose better identified patients without HF-related hospitalizations.

\section{References}

1. McMurray JJ, Adamopoulos S, Anker SD, et al. ESC Guidelines for the diagnosis and treatment of acute and chronic heart failure 2012: The Task Force for the Diagnosis and Treatment of Acute and Chronic Heart Failure 2012 of the European Society of Cardiology. Developed in collaboration with the Heart Failure Association (HFA) of the ESC. Eur Heart J 2012;33:1787-1847. DOI: 10.1093/eurheartj/ehs104.

2. Jencks SF, Williams MV, Coleman EA. Rehospitalizations among patients in the Medicare fee-for-service program. N Engl J Med. 2009;360:1418-1428. DOI: 10.1056/NEJMsa0803563.

3. Gheorghiade M, Pang PS. Acute heart failure syndromes. J Am Coll. Cardiol. 2009;53:557-573. DOI:10.1016/j.jacc.2008.10.041.

4. Bueno $H$, Ross JS, Wang $Y$, et al. Trends in length of stay and short-term outcomes among Medicare patients hospitalized for heart failure, 1993-2006. JAMA. 2010;303:2141-2147. DOI:10.1001/ jama.2010.748.

5. Keenan PS, Normand SL, Lin Z, et al. An administrative claims measure suitable for profiling hospital performance on the basis of 30-day all cause readmission rates among patients with heart fail- ure. Circ Cardiovasc Qual Outcomes. 2008;1:29-37. DOI: 10.1161/CIRCOUTCOMES.108.802686.

6. Krumholz HM, Parent EM, Tu N, et al. Readmission after hospitalization for congestive heart failure among Medicare beneficiaries. Arch Intern Med 1997;157:99-104.

7. Rehman SU, Mueller T, Januzzi JL Jr. Characteristics of the novel interleukin family biomarker ST2 in patients with acute heart failure. J Am Coll Cardiol. 2008;52:1458-1465. DOI: 10.1016/j. jacc.2008.07.042

8. Mueller T, Dieplinger B, Gegenhuber A, et al. Increased plasma concentrations of soluble ST2 are predictive for 1-year mortality in patients with acute destabilized heart failure. Clin Chem. 2008;54:752-756. DOI: 10.1373/clinchem.2007.096560.

9. Boisot S, Beede J, Isakson S, et al. Serial sampling of ST2 predicts 90-day mortality following destabilized heart failure. J Card Fail. 2008;14:732-738. DOI: 10.1016/j.cardfail.2008.06.415.

10. Bayes-Genis A, Pascual-Figal D, Januzzi JL, et al. Soluble ST2 monitoring provides additional risk stratification for outpatients with decompensated heart failure. Rev Esp Cardiol. 2010;63:1171-1178.

11. Manzano-Fernandez S, Mueller T, Pascual-Figal D, et al. Usefulness of soluble concentrations of interleukin family member ST2 as predictor of mortality in patients with acutely decompensated heart failure relative to left ventricular ejection fraction. Am J Cardiol. 2011;107:259-267. DOI: 10.1016/j.amjcard.2010.09.011.

12. Pascual-Figal $D$, Manzano-Fernandez $S$, Boronat $M$, et al. Soluble ST2, high-sensitivity troponin $\mathrm{T}$ - and $\mathrm{N}$-terminal pro-B-type natriuretic peptide: Complementary role for risk stratification in acutely decompensated heart failure. Eur J Heart Fail. 2011;13:718-725. DOI: 10.1093/eurjhf/hfr047.

13. Ky B, French B, McCloskey K, et al. High-sensitivity ST2 for prediction of adverse outcomes in chronic heart failure. Circ Heart Fail. 2011;4:180-187. DOI: 10.1161/CIRCHEARTFAILURE.110.958223.

14. Pascual-Figal DA, Ordoñez-Llanos J, Tornel PL. et al. Soluble ST2 for predicting sudden cardiac death in patients with chronic heart failure and left ventricular systolic dysfunction. J Am Coll Cardiol. 2009;54:2174-2179. DOI: 10.1016/j.jacc.2009.07.041.

15. Bayes-Genis A, de Antonio M, Galán A, et al. Combined use of highsensitivity ST2 and NTproBNP to improve the prediction of death in heart failure. Eur J Heart Fail. 2012;14:32-38.

16. Lupón J, de Antonio M, Galán A, et al. Combined use of the novel biomarkers high-sensitivity troponin $\mathrm{T}$ and ST2 for heart failure risk stratification vs conventional assessment. Mayo Clin Proc. 2013;88:234-243. DOI: 10.1093/eurjhf/hfr156.

17. Wojtczak-Soska K, Sakowicz A, Pietrucha T, Lelonek M. Soluble ST2 protein in the short-term prognosis after hospitalisation in chronic systolic heart failure. Kardiol Pol. 2014;72:725-734. DOI: 10.5603/ KP.a2014.0085.

18. Sobczak S, Wojtczak-Soska K, Ciurus T, et al. Single sST2 protein measurement predicts adverse outcomes at 1-year followup in patients with chronic heart failure. Pol Arch Med Wewn. 2014;124:452-458.

19. Ky B, French B, McCloskey K, et al. High-Sensitivity ST2 for prediction of adverse outcomes in chronic heart failure. Circ Heart Fail. 2011;4:180-187. DOI: 10.1161/CIRCHEARTFAILURE.110.958223.

20. Januzzi JL, Pascual-Figal D, Daniels LB. ST2 Testing for chronic heart failure therapy monitoring: The International ST2 Consensus Panel Am J Cardiol. 2015;115:70B-5B. DOI: 10.1016/j.amjcard.2015.01.044.

21. Felker GM, Fiuzat M, Thompson V, et al. Soluble ST2 in ambulatory patients with heart failure: Association with functional capacity and long-term outcomes. Circ Heart Fail. 2013;6:1172-1179. DOI: 10.1161/CIRCHEARTFAILURE.113.000207.

22. Broch K, Ueland T, Nymo SH, et al. Soluble ST2 is associated with adverse outcome in patients with heart failure of ischaemic aetiology. Eur J Heart Fail. 2012;14:268-277. DOI: 10.1093/eurjhf/hfs006.

23. Anand IS, Rector TS, Kuskowski M, et al. Prognostic value of soluble ST2 in the Valsartan Heart Failure Trial. Circ Heart Fail. 2014;7:418426. DOI: 10.1161/CIRCHEARTFAILURE.113.001036.

24. Volpe M, Rubattu S, Burnett J Jr. Natriuretic peptides in cardiovascular diseases: current use and perspectives. Eur Heart J. 2014;35:419425. DOI: 10.1093/eurheartj/eht466.

25. Boerrigter G, Costello-Boerrigter LC, Burnett JC Jr. Natriuretic pep- 
tides in the diagnosis and management of chronic heart failure. Heart Fail Clin. 2009;5:501-514. DOI: 10.1016/j.hfc.2009.04.002.

26. Cocco G, Jerie P. Assessing the benefits of natriuretic peptidesguided therapy in chronic heart failure. Cardiol J. 2015;22:5-11. DOI: 10.5603/CJ.a2014.0041.

27. Wojtczak-Soska K, Sakowicz A, Pietrucha T, Lelonek M. Soluble ST2 protein in chronic heart failure is independentof traditional factors. Arch Med Sci. 2013;21:9,21-26. DOI: 10.5114/aoms.2013.33344.

28. Januzzi JL, Pascual-Figal D, Daniels LB. ST2 Testing for chronic heart failure therapy. Am J Cardiol. 2015;115:70B-75B. DOI: 10.1016/j.amjcard.2015.01.044.

29. Van de Veire NR, de Winter O, Gillebert TC, de Sutter J. Diabetes and impaired fasting glucose as predictors of morbidity and mortality in male coronary artery disease patients with reduced left ventricular function. Acta Cardiol. 2006;6:137-143.

30. Gotsman I, Shauer A, Lotan C, Keren A. Impaired fasting glucose: A predictor of reduced survival in patients with heart failure. Eur J Heart Fail. 2014;16:1190-1198. DOI: 10.1002/ejhf.146.

31. Habal MV, Liu PP, Austin PC, et al. Association of heart rate at hospital discharge with mortality and hospitalizations in patients with heart failure. Circ Heart Fail. 2014;7:12-20. DOI: 10.1161/CIRCHEARTFAILURE.113.000429.

32. Gaggin HK, Szymonifka J, Bhardwaj A, et al. Head-to-head comparison of serial soluble ST2, growth differentiation factor-15, and highly-sensitive troponin $\mathrm{T}$ measurements in patients with chronic heart failure. JACC Heart Fail. 2014;2:65-72. DOI: 10.1016/j. jchf.2013.10.005.

33. Bayes-Genis A, de Antonio M, Vila J, et al. Head-to-head comparison of 2 myocardial fibrosis biomarkers for long-term heart failure risk stratification: ST2 versus galectin-3. J Am Coll Cardiol. 2014;21(63):158-166. DOI: 10.1016/j.jacc.2013.07.087.

34. Brignole M, Auricchio A, Baron-Esquivias G, et al. 2013 ESC Guidelines on cardiac pacing and cardiac resynchronization therapy: The Task Force on cardiac pacing and resynchronization therapy of the European Society of Cardiology (ESC). Developed in collaboration with the European Heart Rhythm Association (EHRA). Eur Heart J. 2013;34:2281-329. DOI: 10.1093/eurheartj/eht150.

35. Yancy CW, Jessup M, Bozkurt B, et al. 2013 ACCF/AHA Guideline for the Management of Heart Failure. J Am Coll Cardiol. 2013;62:147239. DOI: $10.1161 / \mathrm{CIR} .0 \mathrm{~b} 013 \mathrm{e} 31829 \mathrm{e} 8776$. 